\title{
INTENSIFICAÇÃO DO TRABALHO DOCENTE ADMINISTRATIVO E PROCESSOS DECISÓRIOS DEMOCRATICAMENTE RESTRITOS NA EXPANSÃO/INTERIORIZAÇÃO PRECÁRIA E DESORDENADA
}

\author{
Administrative teaching work intensification and democratically restrict \\ decision-making processes in the disordered and precarious expansion/ \\ interiorization
}

Intensificación del trabajo docente administrativo y los procesos decisivos democráticamente restringidos en la expansión/interiorización precaria y desordenada

RESUMO O artigo toma como objeto de análise os processos decisórios de uma instituição federal de ensino superior em um contexto de expansão, particularmente, de um campus interiorizado. Procura-se demonstrar que a expansão e a interiorização, pautadas pela racionalidade instrumental e gerencial, se caracterizam como precárias e desordenadas, de modo a extensificar e intensificar o trabalho do professor. Argumenta-se que, no caso do professor-gestor e de professores envolvidos com a gestão, a intensificação e a extensificação do trabalho têm implicações negativas sobre o aprofundamento das discussões e processos decisórios, de modo a reduzir as possibilidades de uma democracia representativa, per si já restrita. Desse modo, aponta-se a necessidade de se pensar alternativas para possibilitar debates mais aprofundados e ampliados sobre a expansão da universidade e seus processos decisórios e de inclusão.

PALAVRAS-CHAVE: EXPANSÃO DO ENSINO SUPERIOR PÚBLICO. INTENSIFICAÇÃO E PRECARIZAÇÃO DO TRABALHO. GESTÃO E PROCESSOS DECISÓRIOS. POLÍTICAS EDUCACIONAIS.

ABSTRACT The article takes as the subject of analysis the decisionmaking processes in a higher education federal institution in an expansion context, particularly, of an interiorized campus. It is expected to show that the expansion and the interiorization, guided by the managerial and instrumental rationality, are characterized as precarious and disordered, so that it expands and intensifies the professor's work. It is argued that, in the case of the manager-professor and of professors involved with administration, the intensification and the expansion of the work have negative implications for the deepening of the discussions and decision-making processes, so that it reduces the possibilities
Eduardo Pinto e Silva Universidade Federal de São Carlos - UFSCar

Dayton Fernando Padim Univ. Federal do Oeste da Bahia - UFOB

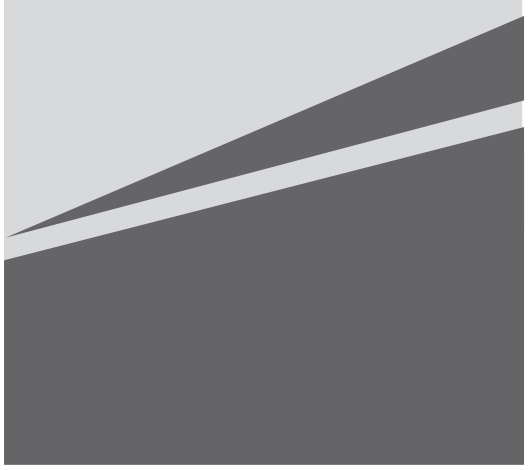


of a representative democracy, per se already restrict. Thus, it is pointed the necessity of thinking about alternatives to enable deeper and more expanded debates about the expansion of the university and its decision-making and inclusion processes.

KEY-WORDS: PUBLIC HIGHER TEACHING EXPANSION. WORK INTENSIFICATION AND DETERIORATION. ADMINISTRATION AND DECISION-MAKING PROCESSES. EDUCATION POLICIES.

RESUMEN El artículo tiene como objeto de análisis los procesos decisivos de una institución federal de enseñanza superior en un contexto de expansión, especialmente, de un campus en el interior. Se busca demostrar que la expansión y la interiorización, basadas en la racionalidad instrumental y gerencial, se caracterizan como precarias y desordenadas, a fin extender e intensificar el trabajo del profesor. Se argumenta que, en el caso del profesor-gestor y de profesores involucrados con la gestión, la intensificación y la extensión del trabajo tienen implicaciones negativas sobre la profundización de las discusiones y procesos decisivos, con el fin de reducir las posibilidades de una democracia representativa, per si ya restringida. Así, se apunta la necesidad de pensar alternativas para posibilitar debates más profundizados y ampliados sobre la expansión de la universidad y de sus procesos decisivos y de inclusión.

PALABRAS CLAVE: EXPANSIÓN DE LA ENSEÑANZA SUPERIOR PÚBLICA. INTENSIFICACIÓN Y PRECARIZACIÓN DEL TRABAJO. GESTIÓN Y PROCESOS DECISIVOS. POLÍTICAS EDUCACIONALES.

\section{INTRODUÇ̃̃o}

A expansão de vagas no ensino superior federal teve início no final do primeiro mandato do presidente Luiz Inácio Lula da Silva, depois de décadas de estagnação. No ano de 2003, o governo federal lançou o Programa de Expansão Fase I, que teve como meta promover a interiorização do ensino superior público, tendo sido, assim, o primeiro passo para a expansão e interiorização das Instituições de Ensino Superior Federal (IFES).

No contexto histórico, social e político da expansão promovida nos governos de Lula, apontava-se que o país precisava melhorar seus índices. Uma das preocupações era que pudesse ser elevada a quantidade de vagas e de matrículas, de modo que pelo menos $30 \%$ da população, com idade adequada de frequentar a universidade, pudesse nela ser incluída. No entanto, temos que lembrar que, apesar da mudança em 2003, para um gover- no dito democrático-popular, houve continuidade nos procedimentos que norteavam a Reforma do Estado desde o octênio de FHC, como medidas neoliberais que impingiam o fazer mais com menos, e utilizar ao máximo os recursos disponíveis.

A expansão deveria ser encarada como uma forma de ampliar o acesso à universidade, cabendo à universidade suprir o mercado com mão de obra qualificada. Em um primeiro momento, no caso do Programa Expandir, visando suprir um déficit de professores da educação básica. Já no REUNI, a preferência foi por cursos ditos interdisciplinares, com uma base comum, nos quais, a posteriori, o aluno decidiria o que preferiria concluir. Tornou-se comum nesses novos cursos percorrer um ciclo básico e, depois, uma fase com conteúdos específicos. Nesse sentido, o MEC, por meio do REUNI, adotou o modelo de educação terciária do Banco Mundial, como sendo desejável e inovador, porque nele haveria 
"diversidade", "mobilidade" e "interdisciplinaridade". Mas tal se realizava sob um viés instrumental e privatista que caracterizou a expansão das IFES e da Educação Superior como um todo. O REUNI seguiu então, senão completamente, ao menos em partes, o modelo europeu proposto pela Declaração de Bolonha. ${ }^{1}$ Sendo assim, os novos campi se diferenciavam da matriz, pois na maior parte das vezes os cursos tinham um caráter mais pragmático de formação de mão de obra qualificada e diplomação (PADIM, 2014).

Assim, o Estado brasileiro se torna, ao mesmo tempo, caudatário e protagonista de práticas neoliberais que, durante o período sui generis de expansão sob o lulismo, expande as federais, mas sob uma redução relativa dos recursos, tomando-se o todo ampliado. Em algumas atividades universitárias a redução de recursos foi bem perceptível, como as relativas ao pessoal das atividades meio. Do ponto de vista social, se priorizaram ações focais, enquanto a sociedade e camadas populares reivindicavam aumento das ações políticas universais e voltadas à integralidade da sociedade civil. Desse modo, a expansão se deparava com interesses ambivalentes, que já estavam postos na adoção de uma política (econômica) de conciliação de classes, e que se colocavam nas demandas relativas à educação superior:

A universidade encontra-se hoje perante o desafio de conciliar interesses ambivalentes, conciliar interesses econômicos e de produção e divulgação de conhecimentos, conhecimentos produzidos pelas pesquisas mantidas por grupos financeiros, conciliar formação profissional e formação cultural (humanística) do indivíduo, conciliar (ou atender?) os anseios de uma sociedade, da qual é parte constituinte, no que se refere à ascensão social pela busca profissional e como fonte produtora de conhecimento, conhecimento este visto por esta sociedade como "salvador", já que é expressão da "verdade" (RODRIGUES, 2004, p. 136).

Nesse sentido, pesquisas realizadas por Sguissardi e Silva Júnior (2009) e Silva Júnior, Sguissardi e Silva (2010) mostraram que, desde a implantação da Reforma do Estado no Brasil, houve intensificação, precarização e extensificação do trabalho docente, com aumento significativo das funções que o docente deve realizar. Por intensificação do trabalho compreende-se o processo no qual o docente, submetido à degradação das condições de trabalho, associada ao acúmulo de tarefas (ensino, pesquisa, extensão e gestão), só as objetivam mediante ampliação do ritmo de sua execução. Mas mesmo com a intensificação, dado o acúmulo e o desgaste, as atividades não se esgotam na jornada de trabalho estabelecida, e a esse plus chamamos extensificação, pois exige o incremento de horas trabalhadas, e não somente sua aceleração.

No caso da unidade acadêmica e da instituição investigada, objeto do presente artigo, mesmo com a criação de um novo campus, que ainda não tem uma estrutura definida para a pesquisa nem para a extensão, professores e técnicos administrativos não deixaram de participar desse processo, e procuraremos evidenciar aspectos dos processos decisórios realizados.

A racionalidade gerencial e heterônoma, e a intensificação e precarização do trabalho, se expressavam nas instituições educacionais federais, em especial nas que, de forma incipiente, se estruturavam em campi interiorizados.

Segundo Silva Júnior, Sguissardi e Silva (2010):
Declaração em Português, Disponível em http://www. ond.vlaanderen.be/hogeronderwijs/bologna/links/ language/1999_Bologna_Declaration_Portuguese. pdf. Acesso em 20/01/2014.
A universidade estatal pública brasileira passa por um processo de mercantilização de sua identidade insti- 
tucional, em função da naturalização do sequestro do fundo público pelo capital, fenômeno que, de imediato, leva à intensificação e precarização do trabalho e, para o que aqui nos interessa, do trabalho do professor-pesquisador das universidades públicas do país (SILVA JÚNIOR, SGUISSARDI e SILVA, 2010, p.12).

No caso específico da nossa investigação, semelhante à intensificação e precarização do trabalho do professor-pesquisador, foi possível tecer análises sobre a figura do professor-gestor. O professor-gestor, nesse caso, são todos os docentes que têm funções administrativas, formalizadas ou não, visto que o professor, que acumula a função de coordenador de curso, tem, de certa forma, um aumento da sua carga de trabalho, com um acréscimo de salário muito pequeno. Já outros docentes que não têm essa função formalizada, mas estão em comissões de planejamento do campus, por exemplo, têm um aumento em sua carga de trabalho, sem receber aumento salarial.

Não queremos aqui dizer que ganhar monetariamente ou não, pela função desempenhada, mude a situação da intensificação. Longe disso, essa divisão, perante a universidade, somente determina os docentes que têm responsabilidade legal, sobre os que não têm. Os dois tipos de professores-gestores estão em um patamar relativamente similar de sobrecarga de trabalho.

Todas as mudanças ocorridas na esfera pública, sobretudo após o fim da ditadura e meados da década de 1980, precisam passar por órgãos decisórios para que, democraticamente, as decisões sejam tomadas. $\mathrm{Na}$ universidade não foi diferente. Ela conta com órgãos de decisão na sua base, que decidem sobre questões pontuais como problemas em cursos, no caso de Conselhos de unidades acadêmicas, e decisões em esferas superiores, como no caso de aprovação ou não de um projeto de expansão da universidade, caso dos Conselhos Superiores. Vale, no entanto, questionar sobre até que ponto as decisões ocorrem de forma efetivamente democráticas, no sentido da amplitude, abrangência e profundidade dos debates.

No caso específico ora analisado, podemos entender que o representante dos processos decisórios é do tipo fiduciário, porque "tem o poder de agir com uma certa liberdade em nome e por conta dos representados, na medida em que, gozando da confiança deles, pode interpretar com discernimento próprio os seus interesses", e tem representação dos interesses particulares, porque "pertence à mesma categoria profissional dos representados, com o que apenas o operário pode representar eficazmente os operários, o médico os médicos, o professor os professores, o estudante os estudantes etc." (BOBBIO, 1987, p. 47).

As universidades têm em seus ConseIhos as tomadas de decisão pelos seus conseIheiros, que no caso das cadeiras reservadas às direções de unidade e coordenações de colegiado de cursos de graduação e pós-graduação, quem as ocupa são os professores-gestores responsáveis pela participação nos órgãos colegiados (colegiado de curso, conselho de unidade, conselhos superiores), votados pelos pares para representá-los nessas instâncias, tendo como pressuposto que as decisões ali tomadas são de interesse da comunidade acadêmica como um todo. Temos como foco uma democracia representativa nesses órgãos de decisão. Todavia, ressaltamos que as composições desses Conselhos não são paritárias.

\section{Metodologia}

A proposta inicial de coleta de dados da pesquisa, cujo recorte das análises ora se apresenta neste artigo, foi a de utilizar questionários, que foram enviados por e-mail para docentes, discentes e técnicos administrativos de todos os cursos de unidade acadêmica fora de sede de uma universidade federal no triângulo mineiro, a fim de buscar informações relevantes de suas concepções e pers- 
pectivas sobre a expansão e interiorização. Também foram realizadas entrevistas com sujeitos previamente selecionados, que de alguma maneira contribuíram para a discussão da implantação ou fizeram/fazem parte dessa construção de um novo modelo de instituição (PADIM, 2014).

A pesquisa foi orientada nos moldes de um estudo de caso, que como relata Godoy (1995, p. 25) "visa ao exame detalhado de um ambiente, de um sujeito ou de uma situação em particular". Utilizou-se para a análise dos dados a metodologia de análise de conteúdo. conceituada como como:

...um conjunto de técnicas de análise das comunicações visando a obter, por procedimentos sistemáticos e objetivos de descrição do conteúdo das mensagens, indicadores (quantitativos ou não) que permitam a inferência de conhecimentos relativos às condições de produção/recepção (variáveis inferidas) destas mensagens (BARDIN, 1977, p. 42).

Foram investigados e analisados discursos de docentes e técnicos administrativos dos cursos de Administração, Ciências Contábeis, Ciências Biológicas, Engenharia de Produção, Física, Geografia, História, Matemática, Pedagogia, Química e Serviço Social. Procurou-se realizar, além da análise de conteúdo dos discursos dos sujeitos pesquisados, análises de documentação e dados objetivos da expansão das IFES.

Para um levantamento preliminar dos dados, foi utilizado um questionário on-line. Este foi aplicado em período específico, acompanhado de instruções para acesso, por e-mail, para os docentes, discentes e técnicos dos respectivos cursos, assim como para os técnicos dos setores meio.

Já as entrevistas semiestruturadas ocorreram posteriormente à sistematização preliminar dos dados dos questionários. Elas foram gravadas e transcritas e realizadas com respondentes selecionados dos respondentes ao questionário. Estabelecemos os seguintes critérios e quantidades: três professores da unidade acadêmica investigada, sendo que pelo menos um deles já tivesse atuado como Diretor da unidade acadêmica e outro como Coordenador de curso; dois técnicos administrativos, sendo um de setor meio e outro da unidade acadêmica investigada. Assim, dois terços dos docentes foram ocupantes de cargos administrativos, com maior contato e participação nos processos decisórios da implantação e desenvolvimento da unidade acadêmica investigada.

No caso dos técnicos, procurou-se entrevistar um do setor meio e outro da unidade acadêmica investigada pois, desse modo, teríamos a possibilidade de registrar e analisar discursos cuja inserção dos sujeitos se dava em planos administrativos relativamente distintos.

\section{RELAÇÕES ENTRE TRABALHO DOCENTE ADMINISTRATIVO INTENSIFICADO E EXTENSIFICADO E PROCESSOS DECISÓRIOS DEMOCRATICAMENTE RESTRITOS}

Observando, então, as novas funções dos docentes, no caso da unidade acadêmica investigada, principalmente em seu início, percebemos que, além das demandas administrativas, recorrentes, e que vêm aumentando com o passar dos anos, tinham que dedicar parte do seu tempo para funções técnicas, como por exemplo, montagem de equipamentos audiovisuais, trâmites internos de secretaria e até mesmo passar informações acadêmicas para os alunos, conforme podemos depreender das declarações a seguir:

Marcos: Eu me adaptei muito bem
aqui, problema nenhum, o pessoal
reclamava muito das condições de
trabalho, a melhor fase que eu tive
de produção acadêmica foi esse
período que eu sai e vim para cá
antes da direção, foi a fase que eu
mais produzi naquele subsolo da 
unidade 1, porque na nossa área de educação com o computador, acabou, não precisa de mais nada. [...] Achava muito estranho o pessoal aqui reclamava muito em uma lista de e-mail, reclamação. Tem gente que se acha melhor que todo mundo então o cara vem para cá achando que passou em um concurso público que ele é um "puta cara", sabe? E ele põe a expectativa que vai chegar a universidade federal e vai ter uma estrutura imensa e não é assim, vê as condições que as universidades estão trabalhando não é simples, o cara tem o gabinete dele e o computador e ele que se vire para resolver o problema dele.

Rafael: Uns até vêm com vontade de ficar, mas percebem que não têm estrutura adequada para eles desenvolverem suas pesquisas, até na questão de ensino mesmo não tinha toda infraestrutura adequada, não temos gabinetes adequados. A matemática, por exemplo, tem 20 professores em uma sala sem divisória não é um local adequado para se fazer pesquisa, até mesmo para preparar uma aula, você precisa ter paz, sossego para poder preparar uma aula e ainda não temos uma reinvindicação de todos os professores, e isso prejudica bastante, então muitos vêm, ficam desiludidos com aquela infraestrutura que não é a melhor possível e vão embora à primeira oportunidade que surgir outro concurso, isso causa uma instabilidade dentro do grupo. [...]. Apoio psicopedagógico para docente e para discente não tem de forma adequada aqui, eu não tenho um apoio psicológico, pedagógico, se eu tiver com uma depressão, por exemplo, para onde que eu vou, serei socorrido por qual órgão, terei que ir para Uberlândia?
Os docentes, principalmente o professor-gestor e seus substitutos legais, tinham, nos colegiados e conselhos, uma das maiores cargas de trabalho, visto que concentravam um grande volume de ações a serem realizadas, quase sempre em pequeno espaço de tempo. Já no caso dos conselhos superiores, para garantir sua participação, os docentes tinham que se dirigir à matriz, depois retornando para as suas atividades corriqueiras na unidade acadêmica investigada. Se fizermos uma conta simples da quantidade de professores que estavam então ligados diretamente com a gestão dos cursos e indiretamente por intermédio dos colegiados, conselho da unidade acadêmica e comissões, se pegarmos um curso médio da unidade acadêmica investigada, como o curso de Química, então com quinze docentes, verifica-se que cinco participavam da reunião de colegiado, pelo menos dois de alguma comissão ou coordenação de laboratório, e outro como substituto legal. Sendo assim, quase metade dos docentes do curso tinham ligação direta ou indireta com a gestão do curso.

$\mathrm{Na}$ ótica do gerencialismo, a administração pública deve orientar suas atividades de modo a garantir controle, eficiência e competitividade. De acordo com Shiroma e Campos (2006), o gerencialismo, no campo educacional, ao contrário dos modelos de administração que lhe precederam, “é um movimento que tenta modificar não só a organização da escola, imprimir outra lógica ao funcionamento do sistema educacional”, visa, principalmente, "operar uma transformação na subjetividade dos educadores, por meio da implantação de mecanismos bastante objetivos de controle que afetam a organização, a avaliação e, portanto, a gestão do trabalho docente".

Nesse contexto, não se encontram suficientes momentos para o debate e a troca de ideias. O trabalho docente tende a se centrar quase que mecanicamente no desenvolvimento de sua atividade fim e de seus resultados. $O$ professor tem sua subjetividade manipulada, senão cooptada, pela racionalidade instrumental (GAULEJAC, 2007), totalmente distinta da 
racionalidade democrática aludida por Habermas, fazendo que o seu trabalho seja direcionado de forma técnica, no qual ele ministra suas aulas, faz suas pesquisas em um meio altamente competitivo, tenta ganhar com isso visibilidade, com pretensão de obter uma forma alternativa de melhorar sua remuneração, por intermédio de bolsa produtividade, entre outros mecanismos que dependem de metas prescritas e resultados mensuráveis. Assim, ao ter sua subjetividade manipulada e/ou cooptada, o professor não encontra meios suficientes para fazer diferente, e traçar alternativas criativas ao prescrito normativo. Condicionado às medidas impostas pelo neotecnicismo e mecanismos gerenciais, orientados primeiramente pelo modelo gerencialista do mercado, por meio de agências de fomento do governo, como CAPES e CNPQ, encontra limitadas condições de um fazer efetivamente autônomo.

Dessa forma, o indivíduo, com sua autonomia limitada, senão controlada, se constitui como alvo da racionalidade instrumental. Entende-se racionalidade instrumental como "a capacidade de calcular probabilidades e desse modo coordenar os meios corretos com um fim determinado" (HORKHEIMER, 1976, p. 13). Gaulejac aponta para definição similar, considerando a racionalidade instrumental como:

A racionalidade instrumental consiste em pôr em ação uma panóplia impressionante de métodos e técnicas para medir a atividade humana, transformá-la em indicadores, calibrá-la em função de parâmetros precisos, canalizá-las para responder às exigências de produtividade (GALEUJAC, 2007, p. 72).

Visto que o aparato produtivo e as mercadorias se impõem ao sistema social como um todo, que a forma política do Estado se deriva da forma-mercadoria (MASCARO, 2013), pode-se dizer que os consumidores dos produtos e das formas de bem-estar social tornaram-se um espécime de prisioneiros do capital. Vivemos, então, na eterna contradi- ção entre produtividade e destruição, dominação e progresso, prazer e infelicidade.

Analisa-se então a relevância das disposições legais da expansão universitária na consolidação de um novo paradigma: as IFES como "escolão", como explanado por um dos entrevistados, pois instituiu e legitimou condições nas quais o que importa é o número de vagas, mesmo que sejam dissociadas do tripé ensino-pesquisa-extensão. Nota-se ainda que esse processo compactua com os fundamentos da Reforma do Estado e com o ajuste da economia brasileira ao capital mundializado. Percebe-se uma nova configuração da cultura e dos métodos universitários no sentido do acolhimento aos pleitos do setor empresarial, bem como aos interesses e necessidades do capital produtivo.

Porém, segundo Luiz e Gomes (2013):

Na forma de governo democrático, o que se pode pressupor com razoável grau de rescisão é que, independentemente das transformações históricas ocorridas no tempo, há elementos que permanecem com relativa estabilidade: são os princípios democráticos de liberdade e igualdade descritos por Aristóteles (1960), atualizados de acordo com os contextos sociais específicos. [...]. A democracia é uma forma de governo que se caracteriza enquanto processo baseado no diálogo argumentativo (deliberação), com vistas à apreensão do bem comum, no qual as decisões (votos) são tomadas pelo maior número possível de envolvidos direta e indiretamente (LUIZ e GOMES, 2013, p. 142-143, grifos dos autores).

Os autores, citados, encontram na Teoria Habermasiana da racionalidade uma via em que as deliberações devem ter como norte o diálogo e a possibilidade do debate, com posicionamentos centrados na razão. Habermas (2002) explica o termo racionalidade: 
Por "racionalidade" entendemos, antes de tudo, a disposição dos sujeitos capazes de falar e agir para adquirir e aplicar um saber falível. [...] Em contrapartida, assim que concebemos o saber como algo mediado pela comunicação, a racionalidade encontra sua medida na capacidade de os participantes responsáveis da interação orientarem-se pelas pretensões de validade que estão assentadas no reconhecimento intersubjetivo. [...] A razão comunicativa encontra seus critérios nos procedimentos argumentativos de desempenho diretos ou indiretos das pretensões de validade proposicional justeza normativa, veracidade subjetiva e adequação estética (HABERMAS, 2002, p. 437).

Sendo, então, a democracia deliberativa, pensada como um processo ancorado no diálogo, na racionalidade e na argumentação, os participantes de colegiados, conselhos e comissões precisam ter condições reais de o fazerem. No entanto, segundo os dados coletados, com uma proporção 70-15-15 (docentes, técnicos e discentes), onde boa parte dos docentes tem seu trabalho intensificado, extensificado e muitas vezes precarizado, podemos perceber que as possíveis decisões tomadas nesses espaços podem não conter o desejo e os anseios dos pares que esses docentes representam.

Diante de tais condições de trabalho do professor, na qual a carga de trabalho é cada vez maior, é de se esperar que, ao participar de atividades que demandam maior empenho, muitos professores não consigam o tempo adequado a fim de aprofundarem seus conhecimentos para subsidiar argumentações fundamentadas, como a realização de projetos de pesquisa interdisciplinar, que necessitam do envolvimento de docentes de diferentes áreas, ou a participação em conselhos e colegiados, nos quais, muitas vezes, discutem temas alheios à formação específica da maioria dos professores.
Todas essas questões levantadas, como intensificação, extensificação e precarização do trabalho docente, gestão gerencialista e racionalidade instrumental, fazem que se estabeleça uma limitação das decisões nos órgãos decisórios. Temos, então, de certa forma, uma democracia restrita, onde o docente tem em suas mãos $70 \%$ dos votos dos conseIhos, é o responsável por várias atribuições, como ministrar aulas, realizar pesquisas, projetos de extensão, ser, muitas vezes, gestor de seu curso ou de alguma parte dele, participar de várias comissões, sendo assim, as decisões tomadas nesses conselhos podem não ter os rumos que necessariamente deveriam. Por sua vez, temos também técnicos com sobrecarga de trabalho e que, muitas vezes, não conseguem acompanhar todas as atividades dos órgãos decisórios, assim como acontece com os discentes que têm uma carga horária de estudo relativamente alta.

Vejamos uma explicação sobre os órgãos colegiados da unidade acadêmica investigada relatado pelo docente Marcos:

Marcos - Todas as decisões passam pelos colegiados, pelo colegiado de curso e pelo Conselho da unidade, porque a Direção não pode decidir nada. Uma decisão que a gente tem que tomar com antecedência ela é formalizada por ad-referendum, depois o Conselho tem que referendar. Não se pode decidir nada sozinho, mas tem uma coisa, mesmo que passe pelos colegiados não significa que seja democrático. A universidade ela não é democrática, ela é hierarquizada. Eu acho que é uma diferença muito grande uma coisa você falar "é democrática porque tem o Conselho"; é discutido no Conselho e as decisões vêm dele, mas é um campo hierárquico que aí um fica dependendo do outro, quer dizer que a estrutura oprime as decisões [...]. Eu sou do pensamento de democracia como participação coletiva das deci- 
sões, isso não acontece, aqui acontece mais que Uberlândia, porque aqui ainda tem muita comissão interna que ajuda a decidir coisas, em universidade mais antiga não tem [...]. Aqui a gente ainda tem comissões que ajudam a pensar e depois manda a decisão para o Conselho da unidade, o Conselho da unidade que vai acima do estudo da Comissão para tomar uma decisão.

Quando perguntados se existia diferença entre os órgãos superiores, colegiados e Conselho da unidade, ficou evidente certa discrepância, vejamos alguns relatos:

Marcos - O CONSUN julga é a política geral da universidade e ai você está contemplado nessa política geral. CONGRAD é política geral da graduação. E CONDIR é política geral das unidades acadêmicas. Agora, quando trata de algo especifico, o Pontal nunca teve um processo barrado, barrado assim vamos dizer, reprovado. Se não passou, voltou para adequar e depois, então, eu não vejo que há uma perseguição com o Pontal [...]. Você não sabe se está passando, se passa e depois vai se ferrar lá na frente, mas eu não percebo uma resistência dos Conselhos contra o Pontal, eu não sinto isso, a gente é mais um lá [...]. São mais de 120 pessoas, é muito grande.... Não termina um ponto de Pauta (...).

Carla - o Conselho não é prático, os Conselhos superiores não andam, porque tem muitas pessoas [...]. A pauta de vinte itens você discuti quatro. Então, você passa dezesseis para outra reunião e junta mais com os que têm naquela [posterior] reunião. O regimento interno da FACIP não foi discutido no CONSUN, isso em 2010. Depois que eu entrei, poucos assuntos foram mandados para o CONSUN, está lá de pauta e não foi discutido, e nem vai ser tão cedo. Nós temos uma demanda muito grande e Conselhos pouco deliberativos. Pela forma que os Conselhos estão reunidos, nós temos um CONSUN hoje com quase 200 pessoas.

Fernanda - Democrático é. Isso porque as discussões são mais intensas, o CONSUN principalmente. O pessoal é mais inteirado, está ali porque quer estar ali. E se preocupam entendeu? Você não chega com um assunto lá e algum detalhe passa despercebido, não passa.

O que percebemos é que os membros dos órgãos superiores são apresentados pelos entrevistados como sendo "mais responsáveis", politicamente mais ativos. Aponta-se ainda que nos Conselhos há grande quantidade de pessoas. Mas pautas extensas não são efetivas. E quando todos opinam, resoluções são difíceis, senão postergadas. Mas as discussões têm que acontecer, independente se é Conselho superior ou de unidade. Mas para isso deveriam todos estar inteirados sobre a pauta da reunião, pois é uma obrigação de todos que compõem o Conselho. Mas isto não parece predominar. Excepcionalmente o que se percebe é que, por terem decisões que afetam mais ou menos, há também um empenho maior ou menor no interesse de entender o que vai ser discutido em cada reunião.

Por conseguinte, a democratização que tanto se propala nos discursos políticos pouco aparece e se mescla a práticas de uma democracia maquiada, muito distante da democracia real ou efetiva, que deveria "ser a expressão de uma sociedade democrática e pluricultural em que se cultiva a liberdade, a solidariedade e o respeito às diferenças"; onde a igualdade jurídica seria encarada como Rui Barbosa (1968) descreveu em seu discurso "Oração aos moços": 
A regra da igualdade não consiste senão em aquinhoar desigualmente aos desiguais, na medida em que se desigualam. Nesta desigualdade social, proporcionada à desigualdade natural, é que se acha a verdadeira lei da igualdade. $O$ mais são desvarios da inveja, do orgulho ou da loucura. Tratar com desigualdade a iguais, ou a desiguais com igualdade, seria desigualdade flagrante, e não igualdade real (BARBOSA, 1968).

Assim, o que se encontra em muitas práticas e discursos não corresponde à igualdade prevista na Constituição, na qual todos deveriam ser iguais perante à lei, independentemente de raça, cor ou credo, e muito menos à de Rui Barbosa. A igualdade geralmente "defendida" tende a ser indiferente à classe social, pois apregoa que todos somos iguais, que devemos respeitar igualmente uns aos outros e respeitar as diferenças. Tais discursos advêm de organismos internacionais, como OCDE, Banco Mundial e UNESCO. E nesse contexto de respeitar as diferenças, pode ser desnudada a desigualdade flagrante, que Rui Barbosa explanava, porque trata os desiguais como se tivessem igualdade de condições.

A democracia que defendemos não compactua com a maior parte do que foi dito no parágrafo anterior. Entendemos a democracia em termos gerais, como uma maneira de desenvolvimento real de participação da população envolvida no processo. Especificamente sobre a universidade, esperamos as decisões advindas dos anseios da comunidade acadêmica, da comunidade externa, dos movimentos sociais, sobretudo se houver a esperança de que haja uma mudança dos paradigmas existentes e impostos, muitas vezes, por modelos econômicos.

Para Mascaro (2013, p. 87), em sua tese de que a forma política do Estado é derivada da forma-valor, ou forma-mercadoria, a democracia se circunscreve no interior de "campos que não alteram as próprias estruturas da reprodução social”. Necessariamen- te pertinentes ao poder normativo e jurídico do Estado, compreendido como elemento terciário da reprodução da expropriação da relação social capital-trabalho, a democracia se circunscreve àquela forma política, ainda que, nas dinâmicas das instituições estatais, e não de suas formas, possa ser mais ou menos elástica: "balizada pelo Direito", argumenta, a "ação política é ampla, livre e voluntariosa", "num espaço que é previamente construído estatalmente"; de modo que, "a forma política do capitalismo dá o limite da própria liberdade da vontade democrática"; e conclui: "se inclinarem pela alteração da socialização político-econômica", "será enfrentado com o bloqueio da própria forma democrática" (MASCARO, 2013, p. 87).

Visto que a democracia representativa e a forma política do Estado dão suporte ao sistema econômico, podemos apontar que o capital encontrou maneiras para conviver pacificamente com a democracia representativa hoje existente na universidade e outras instituições estatais.

Dessa forma, democracia, capitalismo e a Reforma do Estado conseguem conviver em harmonia. Todavia, como mostrou a população no ano de 2013, por meio das manifestações ocorridas, esse modelo político não condiz mais com os anseios da mesma, ou seja, essa democracia representativa, que permeia o executivo e legislativo, não representa, de fato, o povo. Se a democracia é o governo do povo, e o povo não consegue ver suas aspirações sendo representadas pelos seus pares, podemos inferir que o modelo de democracia vigente não é o adequado para o momento histórico que o país vivencia, pode até ter conseguido cumprir seu papel em alguns momentos, mas não parece atender à representação da população de maneira efetiva. Ou, dito de outra forma, não se configura como democracia efetiva, ao menos do modo como aqui atribuímos sentido a esse termo.

Logo, se em um contexto maior, como a política nacional, a democracia representativa não condiz com a realidade que se vivencia, dentro da universidade pública isso 
ocorre desde a criação de seus órgãos decisórios, onde a representatividade é pautada por proporções arbitrárias, quando não excludentes.

No caso da unidade acadêmica investigada, na visão micro, e da matriz em visão macro, em nada se distinguem, já que utilizam a mesma fórmula de representação: 70\% de docentes, $15 \%$ de técnicos e $15 \%$ de discentes, eleitos pelos seus pares. Como vimos, a efetividade do voto e das discussões não tem o mesmo peso. Assim, por exemplo, se na melhor hipótese de um ponto de pauta, onde seja discutida a redistribuição de verbas das unidades para aumentar a quantidade de bolsas moradia e alimentação, os discentes dependeriam de um convencimento, pelo menos, de $35 \%$ dos técnicos e docentes. O mesmo acontece com assuntos de interesses restritos aos técnicos.

Portanto, o modelo utilizado na universidade também não está adequado à realidade em que vivemos, pela não representação paritária da comunidade acadêmica, mas também por não termos representantes da comunidade externa, de grupos sociais e agentes da sociedade em geral. Nesse sentido, para que seja possível a universidade pública de fato se democratizar, não basta apenas ampliar a quantidade de cursos e vagas, é preciso quebrar os "muros", e a sociedade, como um todo, ter o poder de opinar sobre os rumos desse espaço político e de formação de opinião e conhecimento.

Dessa forma, temos hoje, uma universidade em expansão, que tem problemas relativos aos processos democráticos de gestão. Além disso, percebemos uma lógica perversa nesse processo de expansão, pois, é realizado de forma desordenada, condicionado totalmente a uma visão de mercado imposta externamente por meio de órgãos governamentais, agregando professores cada vez mais com condições de trabalho desfavoráveis, sendo esse trabalho intensificado dia a dia, assim como técnicos com os mesmos problemas e discentes que ingressam na universidade com um grau de conhecimento cada vez menor, por defasagens oriundas do ensino fundamental e médio.

Tal panorama contribui para que a almejada democratização da educação superior não ocorra da maneira esperada, pois se a mesma estivesse dando certo, não teríamos altos índices de evasão e retenção, como no caso da unidade acadêmica investigada. Sendo assim, essa nova instituição criada para que houvesse um aumento nos índices de pessoas com idade entre 18 a 24 anos no Ensino Superior, não consegue ter um resultado significativo.

Além disso, quando essa instituição consegue formar os profissionais, os mesmos têm pouco acesso a projetos de pesquisa e, dependendo do curso, não têm acesso algum a programas de extensão, como se pode verificar na entrevista da técnica Fernanda. Neste sentido, o profissional que deveria ser formado com uma qualidade desejável, infelizmente vai para a pós-graduação ou para o mercado de trabalho sem experiências que contribuiriam para um melhor desenvolvimento de suas atividades após a conclusão do curso superior.

Uma alternativa à democracia representativa que temos hoje, pouco ou insuficientemente deliberativa, necessita ser repensada e revista. Para que isso ocorra, os regimentos internos e dos conselhos precisam ser discutidos fora desse contexto, de forma a evitar a legislação em causa própria, tal como ocorre nas assembleias legislativas, onde, por exemplo, o deputado ou senador reajusta o seu próprio salário. Sendo assim, propomos que a visão de democracia dentro da universidade seja próxima do que Bobbio explica em seu livro "O futuro da democracia - Uma defesa das regras do jogo", onde conceitua a democracia direta e representativa e aponta seus pontos negativos e positivos. O ponto positivo da democracia direta é a possibilidade de cada cidadão se inteirar e participar ativamente das decisões; e o da democracia representativa é a facilidade de algumas pessoas representarem a opinião de uma quantidade de pessoas. Já o ponto 
negativo da primeira é que as pessoas não têm tempo, muito menos espaço para discussão coletiva, e também a questão da inviabilidade humana, visto que é praticamente impossível, por exemplo, em uma cidade, com mais de cinco mil pessoas, realizar diretamente as decisões; no caso da democracia representativa o ponto negativo é a tomada de decisões que não correspondem à maioria dos representados, ou seja, as decisões são tomadas de acordo com o que o representante com sua bagagem de vida pensa ser a melhor decisão. Depreende-se que um conceito de democracia mais próximo do que o autor argumenta, teria os pontos positivos dos dois conceitos de democracia, e ainda ampliaria esses com a participação cada vez maior da população. Desse modo, quando temos discussões como, por exemplo, a presença da Polícia Militar dentro de campus de uma Universidade Federal, torna-se totalmente necessário que a comunidade, tanto externa quanto interna, debata e chegue a uma decisão pautada cada vez mais na razão e na coletividade.

Uma descrição provável do conceito de democracia que propomos é que exista a representação, mas que os votos tenham o mesmo peso em todos os conselhos. Além disso, as pautas dos conselhos devem ser classificadas com um índice de importância de debate, de modo que as pautas de média a alta importância possam ser submetidas a discussão das bases dos órgãos representados. Sendo essa discussão por meio de fóruns, assembleias e reuniões, onde os representados possam dar sua opinião sobre determinada decisão a ser tomada.

Todo esse processo gera um esforço muito grande, por isso entendemos que esses representantes precisam ter tempo para que possam se dedicar ao que se propõem. Neste sentido, todos os envolvidos precisam ter suas cargas de trabalho ou, no caso dos alunos, de aulas, diminuídas durante o período em que forem representantes. Além disso, esse período não pode ser muito extenso para que não haja complicações para a forma- ção dos alunos representantes ou ainda para os técnicos e docentes que almejam desenvolver outros trabalhos.

O mesmo pode ser aplicado à comunidade externa. Com essas medidas, a formação democrática de todos aumenta, seja sendo representante, seja nas assembleias. Principalmente, a participação efetiva da comunidade externa, rompendo, então, os muros da universidade, deixando que a população que custeia a universidade possa opinar sobre seus rumos. Ou, que os próprios atores da universidade estejam mais intensa e organicamente articulados às demandas da maioria da população, sobretudo daqueles que sofrem com piores condições socioeconômicas e culturais.

\section{ConsideraÇões Finais}

Neste artigo, procuramos explicitar que este aspecto singular da unidade acadêmica investigada não deve, no entanto, ser compreendido como encerrado nele mesmo, mas sim como algo que de certa forma pode ser considerado previsível quando levamos em conta, criticamente, o contexto mais amplo das IFES, da Reforma do Estado e da subsunção da economia e da política à sociabilidade produtiva e ao pragmatismo e viés privatista da ideologia gerencialista. Esta se pauta numa racionalidade instrumental um tanto distinta da racionalidade democráticodeliberativa. Ademais, esta, por si só, não seria uma garantia de um processo democrático efetivamente aglutinador e catalizador de transformações profundas, desejáveis para que a maior parte do povo brasileiro pudesse alcançar condições de vida e trabalho minimamente mais dignas.

Assim, consideramos, com base na análise dos dados que, na implantação e desenvolvimento na unidade acadêmica investigada, houve planejamento insuficiente e desordenado e que, na maior parte das vezes, se concretizaram de forma ainda mais problemática em virtude das relações de poder e do caráter 
democrático restrito dos processos decisórios.

O problema de uma intensificação de trabalho em um setor (acadêmico) amplia o problema de intensificação do trabalho em outro (administrativo) e vice-versa, a intensificação do trabalho acadêmico traz prejuízos à própria qualidade do trabalho acadêmico, e também acarreta em menor disposição para o trabalho administrativo, e este, também por ser intensificado, enfrenta limitações na sua qualidade, limitações estas que são agravadas pela primeira e vice-versa, sendo então um ciclo que só tende a se agravar e se tornar contínuo.
A democracia restrita analisada na unidade acadêmica investigada e sua relação com a sociabilidade produtiva e racionalidade instrumental que atinge o Estado e instituições não se coaduna, portanto, com um projeto universitário e societário efetivamente transformador, mas sim, predominantemente, com processos de inclusão insuficiente, senão excludente. Inclusão excludente que coexiste ao lado de exclusão includente, que, de sua parte, arrasta milhares de jovens para formas de sociabilidade à margem da formação escolar ou universitária, e também do mundo do trabalho, submetendo-os à condição de relegação ou nadificação social.

\section{REFERÊNCIAS}

BARBOSA, R. Oração aos moços. Rio de Janeiro: Tecnoprint, 1968.

BARDIN, L. Análise de conteúdo. Lisboa: Edições 70, 1977.

GAULEJAC, V. Gestão como doença social: ideologia, poder gerencialista e fragmentação social. São Paulo: Idéias \& Letras, 2007

GODOY, A. S. Pesquisa qualitativa - tipos fundamentais. Revista de Administração de Empresas, v. 35, n. 3, mai./jun., 1995, p. 25.

HABERMAS, J. O discurso filosófico da modernidade: doze lições. Tradução de Luiz Sergio Repa e Rodnei Nascimento. São Paulo: Martins Fontes, 2002.

HORKHEIMER, M. Eclipse da razão. Rio de Janeiro: Labor do Brasil, 1976.

LUIZ, M. C.; GOMES, R. M. Políticas públicas educacionais e o conceito de democracia: algumas perspectivas. In: Desafios para a gestão municipal da educação, Xamã, 2013.

MASCARO, A. L. Estado e forma política. São Paulo: Boitempo, 2013.

PADIM, D. F. A expansão e interiorização da Universidade Federal de Uberlândia: um processo de democratização? São Carlos, SP: Universidade Federal de São Carlos, Programa de Pós-Graduação em Educação (Dissertação de Mestrado), 2014.

RODRIGUES, M. M. A instabilidade da universidade vista a partir das contradições geradas de suas crises de hegemonia, de legitimidade e institucional. In: SCRIPTORI, Carmen Campoy (Org.). Universidade e conhecimento: desafios e perspectivas no âmbito da docência, pesquisa e gestão. Campinas: Mercado de Letras, 2004.

SGUISSARDI, V.; SILVA JUNIOR, J. R. O trabalho intensificado nas federais: pós-graduação e produtivismo acadêmico. São Paulo: Xamã, 2009.

SHIROMA, E. O.; CAMPOS, R. F. La resignificación de la democracia escolar mediante el discurso gerencial: liderazgo, gestión democrática y gestión participativa. In: Myriam Feldfeber; Dalila 
Andrade Oliveira (Org.). Políticas educativas y trabajo docente: nuevas regulaciones, nuevos sujetos? Buenos Aires: Ed. Novedades Educativas, 2006, p. 221-237.

SILVA JÚNIOR, J. R.; SGUISSARDI, V.; SILVA, E. P. e. Trabalho intensificado nas federais públicas brasileiras. Universidade e Sociedade, Brasília, DF, v. 45, p. 9-37, jan. 2010.

\section{SOBRE OS AUTORES}

\section{EdUARDo PINTO E SiLVA}

Graduação em Psicologia PUC-SP e Mestre e Doutor em Educação UNICAMP. Pós-doutorado pelo PPFH UERJ. Prof. Associado II da UFSCar, Depto. de Educação e Programa de Pós-Graduação em Educação.

E-mail:dups02@gmail.com

\section{DAYTON FERNANDO PADIM}

Atualmente, professor no Centro das Ciências Exatas e das Tecnologias da Universidade Federal do Oeste da Bahia - UFOB na área de Ensino de Química. Participou como professor substituto no Instituto de Química da Universidade Federal de Uberlândia - UFU entre 2014 e 2015, formado em Licenciatura em Química pela Universidade Federal de Uberlândia, unidade acadêmica FACIP, Mestrado em Educação pela Universidade Federal de São Carlos - UFSCar. E-mail: dayton@ufob.edu.br

Recebido em: 07/06/2017

Aprovado em: 25/06/2017 